Commentary

\title{
News, Ads, Chats, and Property Rights over Algorithms
}

\author{
Jan Kleinnijenhuis \\ Department of Communication Science, Vrije Universiteit Amsterdam, 1081HV, Amsterdam, The Netherlands; \\ E-Mail: j.kleinnijenhuis@vu.nl
}

Submitted: 6 June 2018 | Accepted: 11 June 2018 | Published: 28 September 2018

\begin{abstract}
The success of tech firms rests on their ownership of the algorithms for operating new platforms for the interactions among five groups of stakeholders in the markets of news, ads, and chats: stakeholders from the spheres of politics, journalism, the citizenry, the tech firms themselves, and other firms. Recent regulations that touch on property rights such as the German Netzwerkdurchsetzungsgesetz and the European Directive on Copyright in the Digital Market have turned ownership of algorithms into exclusive ownership. Thereby tech firms obtain also the right to censor and the exclusive right to micro-target clients for advertisers. Coase's theorem is used to discuss alternative allocations of property rights that could improve the quality of news, ads, and chats.
\end{abstract}

\section{Keywords}

algorithms; networks; property rights; social media; tech industry

\section{Issue}

This commentary is part of the Multidisciplinary Issue of Media and Communication, edited by Epp Lauk (University of Jyväskylä, Finland) and Raul Reis (Emerson College, USA).

(C) 2018 by the author; licensee Cogitatio (Lisbon, Portugal). This article is licensed under a Creative Commons Attribution 4.0 International License (CC BY).

\section{Introduction}

"I'm a lawyer and I have no idea what that means" declared Republican Senator Lindsey Graham while holding up the Facebook Terms of Service in the Congressional Hearing regarding Facebook on April 10th, 2018 (C-Span, 2018). In spite of such objections, the US Congressional Hearing, the German Netzwerkdurchsetzungsgesetz (NetzDG) ${ }^{1}$ of January 2018 , the General Data Protection Regulation (GDPR) ${ }^{2}$ of May 2018, and the Directive on Copyright in the Digital Market ("Copyright Directive", approved by the European Parliament in September 2018; expected implementation in laws of the European Union (EU) member states in 2019$)^{3}$, all push in the direction of giving even more rights to tech firms: first, the right to use their algorithms to censor, as well as the exclusive right to use their algorithms to microtarget their users with messages from firms and advocacy groups who pay for this.
NetzDG encourages internet platforms to censor. Fines of up to 5 million euros may be imposed (4.2) if they do not remove client postings with offending content. NetzDG may promote advocacy groups to accuse their political opponents of hate speech, so as to cause tech firms to block or remove opinionated messages of their opponents. In the Congressional hearing, Facebook's CEO, Mark Zuckerberg announced that, by the end of 2018, 20,000 people will work on content review. Ultimately more advanced Al algorithms "would block millions of fake accounts each day at the point of creation before they do any harm" (Facebook, 2018, p. 110). The Copyright Directive forces tech firms explicitly to develop "effective content recognition technologies" which enable censorship. These technologies should enable tech firms to let its users pay for linking to news items from media companies (11, "link tax") and to prevent its users from uploading or disseminating copyrighted materials (13, "upload filter"). According to a group of the inter-

\footnotetext{
${ }^{1}$ https://www.gesetze-im-internet.de/netzdg/NetzDG.pdf

2 https://gdpr-info.eu/

${ }^{3}$ Copyright Directive proposal 2016: https://eur-lex.europa.eu/legal-content/EN/TXT/?uri=CELEX:52016PC0593. Amendments European Parliament September 2018 http://www.europarl.europa.eu/sides/getDoc.do?type=TA\&language=EN\&reference=P8-TA-2018-0337
} 
net's architects, including Vincent Cerf (internet protocol TCP/IP) and Timothy Berners-Lee (World Wide Web protocol HTTP), this is "an unprecedented step towards the transformation of the internet from an open platform for sharing and innovation, into a tool for the automated surveillance and control of its users" (Cerf et al., 2018).

An exclusive ownership right given to tech firms to use their algorithms to micro-target users with third party messages swings the pendulum back. In 2013, Facebook, for example, offered its users the right to use Facebook's GraphSearch algorithm to explore the preferences of friends of friends. According to Alexandr Kogan, who used GraphSearch to scrape Facebook user data for CambridgeAnalytics, scraping was quite common at that time. The try-out was stopped in December 2014 because of privacy issues and because its use made Facebook slow. In 2018, Mark Zuckerberg could easily state, therefore:

In 2014, to prevent abusive apps, we announced that we were changing the entire platform to dramatically limit the data apps could access. Most importantly, apps like Kogan's could no longer ask for data about a person's friends unless their friends had also authorized the app. (Zuckerberg, 2018)

Future advertisers and campaigners will have to pay the tech firms to use their graph search algorithms for microtargeting. As a result, the tech firms earn the largest share of advertising revenues, although algorithm owners may decide to let successful vloggers share in advertisement revenues once they attract many new clients (YouTube), or put advanced social media monitoring tools such as CrowdTangle at the disposal of media companies so as to maximize the audience for their news items on their social media pages (Facebook). Thus, tech firms who own the search algorithms that link their users to news content provided by media companies help to increase the traffic to the websites of these media companies, which enables the latter to sell advertisement space on their own websites. In advance, media companies did contribute to the traffic towards the search algorithms of tech firms, and therefore to the advertising revenues of tech firms, with the cumulative supply of their latest news content. Only a fraction of the search algorithm users in search of news content click on the news snippets or news summaries from media companies that tech firms show to them. Only a fraction reaches the websites of media companies. This explains why the advertisement revenues of tech firms went up disproportionally as compared to those of media companies. This explains also why tech companies are opposed to the Copyright Directive that would reward media companies for the traffic that tech companies can attract by providing links to, or using links to, news content provided by media companies. According to UK Music, Google alone spent more than 30 million euro in its successful lobby to depict the Copyright Directive as the end of an open internet with free links to other websites (UK Music, 2018). Google exploited its ownership of the Pagerank algorithm by inducing the main German media companies, who feared the removal of online links to their news articles on NetzDG copyright grounds, to undermine NetzDG by entering into zero price licenses with Google. With $\$ 7.4$ million in litigation costs against Google, the German association of media companies could use NetzDG to let Google pay out $€ 0.7$ million to media companies who were not satisfied with a zero price license (Ehle, 2018). The legitimacy of media companies in such judicial battles is low because news content is delivered by journalists, while media tycoon companies appear to want to become tech firms themselves by investing less in journalism than in online presence and marketing.

Here we will take Coase's theorem as the point of departure to answer the research question whether alternative allocations to stakeholders of property rights over algorithms would result in a lower price, or a higher quality of news, ads, and/or chats.

\section{Coase Theorem}

Ronald H. Coase (1910-2013) received the 1991 Noble prize "for his discovery and clarification of the significance of transaction costs and property rights for the institutional structure and functioning of the economy". Property rights apply to palpable objects that you are holding in your hands, but also to land, labor force, money, assets, debt certificates, futures, patents, radio frequencies, and network algorithms.

The Coase theorem holds that if property rights are allocated and protected by a Sovereign, and transaction costs are independent of who holds the property rights, then parties will negotiate about the price of benefitting from the use of such property. They will agree on the same price, regardless of who holds the property rightswhat differs is merely who has to pay the price (Coase, 1960/2013). A classic "reciprocal" example is that river delta inhabitants who want to prevent the pollution of the river will be ready to pay the same price to mountain inhabitants who own the river, as the price that mountain inhabitants are ready to pay to dump their polluted waste in the river owned by the river delta inhabitants.

Coase developed his theorem in the context of his investigations into the lack of explicit ownership over radio frequencies in the first half of the previous century (Coase, 1959/2013). To be able to develop a judicial framework to settle disputes about the interference of different radio signals, the government should use its sovereignty to allocate property rights, just as Thomas Hobbes' Sovereign (Hobbes, 1660/2002). This could be achieved by having auctions to sell radio frequencies to the highest bidder. Without property rights, the legal system would keep producing inconsistent jurisdiction as to whether government agencies had any discretion to refuse a radio license, and whether refusing a radio li- 
cense was a violation of the constitutional freedom of the press.

Just as radio programs relate to radio frequencies which allow the targeting of citizens and firms within a geographical area, so do chats, ads, news, and data relate to algorithms which allow for the micro-targeting of specific firms or citizens. The claim of this article is that, just as disputes over the constitutional freedom of the press were solved by government regulations to establish ownership of radio frequencies, disputes over the freedom of expression versus surveillance, censorship, and control can be solved in part by new government regulation regarding property rights over network algorithms.

The Coase theorem urges us to ask which stakeholders are involved, whether property rights are sufficiently clear and whether transaction costs sufficiently low to negotiate a deal.

\section{Stakeholders to Whom Property Rights Could Be Allocated}

Tech firms own network algorithms. Basically, a network algorithm relies on relationships $\mathrm{R}$ between concepts $X$ and $Y$, that could be modeled as RDF-triplets. It derives "transitive" logical conclusions, for example whether $X$ will presumably like $Z$ based on information about the relationship of $X$ to $Y$, and of $Y$ to $Z$, e.g., conclusions about a book $Z$ that $X$ may want to read, given the resemblance between book $Z$ and a book $Y$ that was already bought by $X$. The network algorithm that underlies the righthand side of Google pages, for example, often offers a better comparison of industries and products than web pages of individual organizations filled with PR clichés.

To think about possible alternative allocations of property rights over network algorithms in the market of news, advertisements, and chats, Figure 1 shows a simplified model with five groups of stakeholders from the spheres of the network algorithm firms themselves, other firms, politics, journalism, and the citizenry.

Within a few decades, network algorithm firms-e.g., Google, Amazon, Facebook, Yahoo Finance, Bloomberg, Thomson Reuters' Datastream, and RELX's LexisNexisbecame "semi-benevolent information monopolies" (Karpf, 2018) which established new relations with the other four types of actors. More importantly, they also afforded new relations between the latter. To relate Figure 1 above to its explanation below, italics will be used for the newly afforded relationships between the stakeholders that are printed as arrow labels in Figure 1.

Tech firms offer the platforms, data, and information, on which firms, financial markets, citizens and politicians rely. They deliver citizens a new platform to chat with other citizens, sometimes in their roles as voters or consumers. They allow firms, both in the $B 2 B$ - and

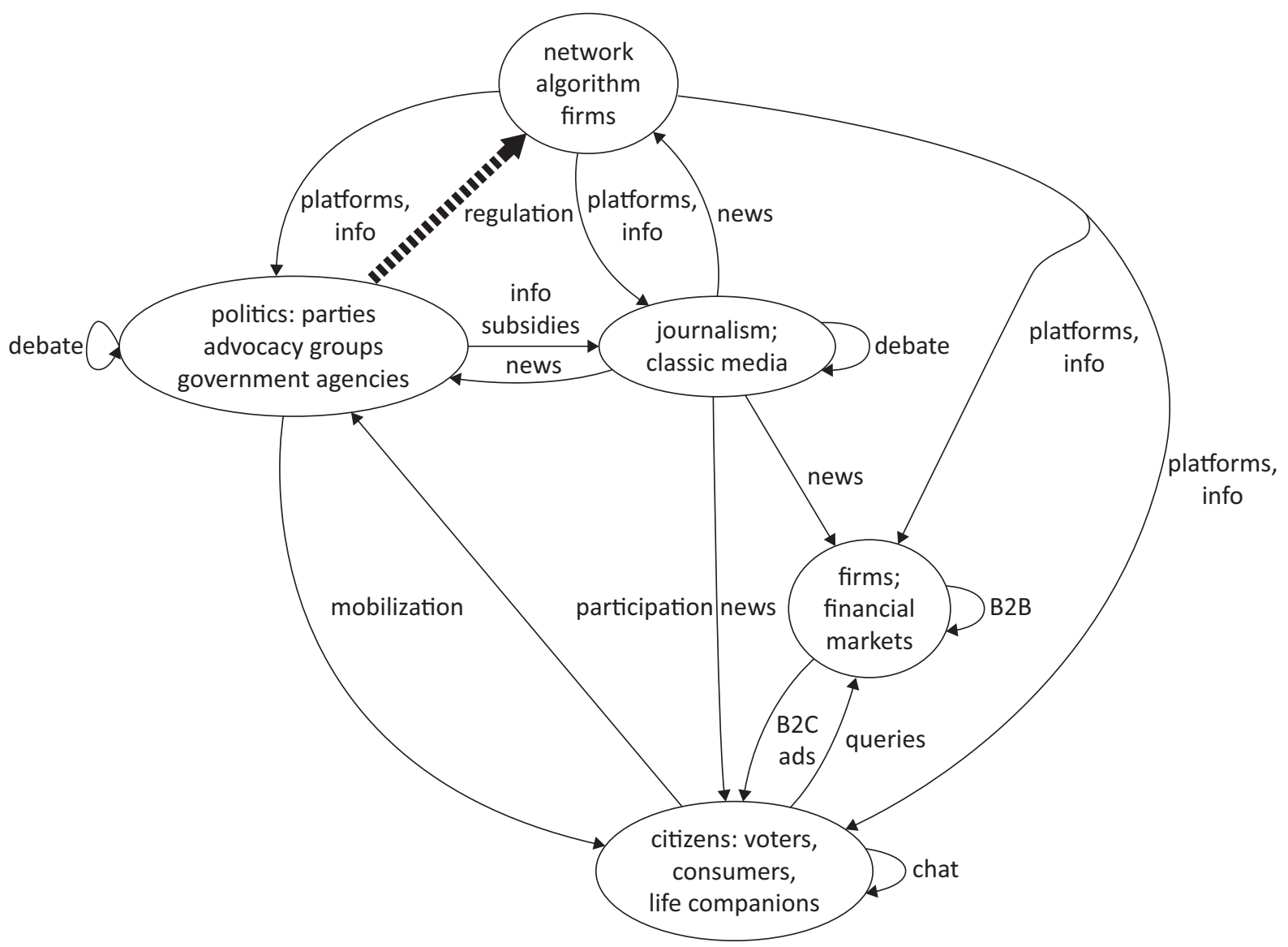

Figure 1. Reciprocal relations between network algorithm stakeholders in the market of news, ads, and chats. 
B2C-markets, to micro-target consumers with ads. Their social media algorithms offer parties, advocacy groups, and government agencies a means to mobilize citizens to participate, share, contribute or vote. Tweets and Facebook posts from politicians have become a new political information subsidy (Cook, 1998) to journalism, in combination with the social media metrics to guess their impact. It is a weird symbiotic relationship, in which attack tweets especially, among others on media and journalists, increase likes and retweets (Lee \& Xu, 2018). The resulting social media storm is often a basis for news in classic media, even when the tweets were not initially deemed newsworthy (Wells et al., 2016).

Social media have become a major portal to access news items from classic media, although online surveys somewhat overestimate their use (Newman, Fletcher, Kalogeropoulos, Levy, \& Nielsen, 2018). The news supply of classic media is split into separate news items with a standard format whose clickbait is routinely assessed with A/B tests. Relatively slow news in classic media about political and financial networks nevertheless exerts not only an influence on public support for political candidates (Wells et al., 2016), but also a long-term influence on financial markets (Kleinnijenhuis, Schultz, Oegema, \& van Atteveldt, 2013; Kräussl \& Mirgorodskaya, 2017). The relevance and influence of news is not captured in price information in the way that modernists like Smith ("the invisible hand") and Karl Marx ("hinter dem Rücken der Produzenten") predicted. Classic media are still the major source of online news (Thurman \& Schifferes, 2012), but their advertising revenues are decreasing because the advertising revenues of the tech firms who disseminate their news are increasing.

\section{Price and Quality of News, Ads, and Chats After Alternative Allocations of Algorithm Ownership}

The puzzle to solve is whether an alternative allocation of algorithm ownership would result in a lower price, or a higher quality, of news, ads, and chats.

A re-allocation that simply would not work is to split giant tech firms into parts. The parts would have a strong incentive to cooperate to serve advertisers with potential customers everywhere and to serve users with friends everywhere. Prices would remain largely unaltered, in line with the Coase theorem. A functional split, similar to the split in the banking sector between investment banks and consumer banks, would not work either, because there is no business model for news or chats without ads, and no model of democracy based on quality news without chats and debate.

The European GDPR grants internet users ownership over their personal data, without providing them with an efficient means to sell it. Therefore, they have to deliver them for free by clicking a thousand times that they accept all cookies before they can carry out business as usual.

More radical ways to split up property rights may not work either because transaction costs, which are primar- ily energy costs in the case of the internet, would be much higher. The enormous energy costs of the current internet are negligible when compared to an internet in which unsupervised high-frequency crypted transactions between all users would be required (i.e., blockchain technology) and in which moreover blocking or removing of specific content would be both content specific (e.g., censorship, copyright) and user specific (e.g., various ratings of social credit). For the same reason, incredibly high transaction costs would result if property rights of graph search algorithms were granted to firms, journalists, and political agencies so that individual internet users would have to pay time and again to avoid being micro-targeted. High transaction costs that threaten the internet will result also if EU member states would make a mess out of property rights by implementing the link tax and the upload filter from the Copyright Directive ambiguously or inconsistently so that many different parties in EU member states may go to court to claim on very different grounds that tech companies violated their property rights over news items, texts, music, films, video clips, art, patents, intellectual property, or art.

Re-allocating the ownership of a part of the network algorithms invented by tech firms to stakeholders from the spheres of journalism, politics, firms and the citizenry could however prevent that tech firms obtain a right to censorship, and even an obligation to censorship, like in NetzDG, GDPR and the Copyright Directive. It's too optimistic to assume that censorship by tech firms would always reckon with old heuristics like "facts are sacred, comments are free" or with the detached ways in which the press quotes or paraphrases subjective sources (Baden \& Tenenboim-Weinblatt, 2018; Van Atteveldt, Sheafer, Shenhav, \& Fogel-Dror, 2017). A reallocation of property rights over algorithms should allow stakeholders to bring their cases to court, and should allow judges to make consistent judgements based on vested property rights. "The legislation must refer to the algorithm" (Lodder \& Loui, in press). It should be noted that legislation to oblige property owners to give others full access to their records is by no means a new phenomenon. For example, farmers who own land and livestock are obliged by law to give full access to their milk production, manure disposal and use of pesticides. To remove the sting from the Copyright Directive "upload filter" (13), it would be helpful to oblige tech firms to equip firms and citizens like authors and artists with the ownership over advanced monitoring tools to inspect whether their copyright is violated. New fast-track procedures would enable firms, authors and artists to go to court, and would enable judges to shape judicial precedents by commanding tech firms to remove the links to materials with specific features in terms of copyright. This digital copyright should not apply to everything, for example not to news content to which the "link tax" applies, and not to materials whose "linkability", thus whose online availability, occurred with the privity of the artist. To remove the sting from the "link tax" (11), it would be help- 
ful to oblige tech firms to equip media companies with the ownership over advanced monitoring tools to register, first, the amount of search queries by internet users that resulted in prominent links to news content delivered by media companies, next to verify that tech firms did not promote news content from media companies who undermine the link tax by not collecting it, and to verify that the link tax is paid directly to the editorial staff of a medium website rather than to the media companies of media tycoons. The link tax should apply only to tech firms with a business model to raise advertisements by attracting users who search for news content, and not, for example to Wikipedia, researchers, teachers or interested citizens. Splitting up the property rights over algorithms of the "semi-benevolent information monopolies" (Karpf, 2018) may reduce automated surveillance and control, and increase the quality of news, ads, and chats.

\section{Acknowledgments}

The author is grateful to John Faasse, Wouter van Atteveldt, and Kasper Welbers for comments and suggestions.

\section{Conflict of Interests}

The author declares no conflict of interests.

\section{References}

Baden, C., \& Tenenboim-Weinblatt, K. (2018). Viewpoint, testimony, action. Journalism Studies, 19(1), 143-161. https://doi.org/10.1080/1461670X.2016. 1161495

C-Span. (2018). Facebook CEO Mark Zuckerberg hearing on data privacy and protection (Video broadcast). C-Span. Retrieved from www.c-span.org/video/ ?443543-1/facebook-ceo-mark-zuckerberg-testifiesdata-protection\&utm_source=fark\&utm_medium= website\&utm_content=link\&ICID=ref_fark

Cerf, V., Berners-Lee, T., Esterhuysen, A., Kahle, B., Behlendorf, B., Schneier, B., . . . Cook, W. (2018). Letter to the President of the European Parliament. Retrieved from https://www.eff.org/files/2018/ 06/13/article13letter.pdf

Coase, R. H. (2013). The Federal Communications Commission. Journal of Law and Economics, 56(4), 879-915. (Original work published 1959)

Coase, R. H. (2013). The problem of social cost. Journal of Law and Economics, 56(4), 837-877. (Original work published 1960)

Cook, T. (1998). Governing with the news. Chicago, IL: University of Chicago.

Ehle, K. (2018, July 17). European Parliament voted 318 To 278 against the amendment proposal for a copyright directive for the digital single market. Mondaq. Retrieved from http://www.mondaq.com/ germany/x/719704/Copyright/European+Parliament
+ Voted+318+to+278+Against+the+Amendment+Pro posal+for+a+Copyright+Directive+for+the+Digital+ Single+Market

Facebook. (2018). Hearing: Facebook, social media privacy, and the use and abuse of data (Memorandum). Washington, DC: Committee on Commerce, Science, and Transportation. Retrieved from www.commerce. senate.gov/public/_cache/files/9d8e069d-2670-4530 -bcdc-d3a63a8831c4/7C8DE61421D13E86FC6855CC 2EA7AEA7.senate-commerce-committee-combinedqfrs-06.11.2018.pdf

Hobbes, T. (2002). Leviathan. Orchard Park, NY: Broadview Press. (Original work published 1660)

Karpf, J. (2018). Learning to live among semi-benevolent information monopolies (Working Paper). Prague: International Communication Association.

Kleinnijenhuis, J., Schultz, F., Oegema, D., \& van Atteveldt, W. (2013). Financial news and market panics in the age of high-frequency sentiment trading algorithms. Journalism, 14(2), 271-291. https://doi.org/ 10.1177\%2F1464884912468375

Kräussl, R., \& Mirgorodskaya, E. (2017). Media, sentiment and market performance in the long run. The European Journal of Finance, 23(11), 1059-1082. https://doi.org/10.1080/1351847X.2016.1226188

Lee, J., \& Xu, W. (2018). The more attacks, the more retweets: Trump's and Clinton's agenda setting on Twitter. Public Relations Review, 44(2), 201-213. https://doi.org/10.1016/j.pubrev.2017.10.002

Lodder, A. R., \& Loui, R. (in press). Data algorithms and privacy in surveillance: On stages, numbers and the human factor. In W. Barfield \& U. Pagallo (Eds.), Research handbook of law and artificial intelligence. Cheltenham: Edward Elgar.

Newman, N., Fletcher, R., Kalogeropoulos, A., Levy, D. A., \& Nielsen, R. K. (2018). Reuters Institute digital news report 2017. Oxford: Reuters Institute.

Thurman, N., \& Schifferes, S. (2012). The future of personalization at news websites. Journalism Studies, 13(5/6), 775-790. https://doi.org/10.1080/ 1461670X.2012.664341

UK Music. (2018, July 3). UK Music chief slams Google as "corporate vultures" as figures show Google's $€ 31 \mathrm{~m}$ EU lobbying bid. UK Music. Retrieved from https:// www.ukmusic.org/news/uk-music-chief-slams-google -as-corporate-vultures-as-figures-show-googles-3

Van Atteveldt, W., Sheafer, T., Shenhav, S. R., \& FogelDror, Y. (2017). Clause analysis: Using syntactic information to automatically extract source, subject, and predicate from texts with an application to the 2008-2009 Gaza War. Political Analysis, 25(2), 207-222. https://doi.org/10.1017/pan.2016.12

Wells, C., Shah, D. V., Pevehouse, J. C., Yang, J., Pelled, A., Boehm, F., ... Schmidt, J. L. (2016). How Trump drove coverage to the nomination: Hybrid media campaigning. Political Communication, 33(4), 669-676. https://doi.org/10.1080/10584609.2016.1224416

Zuckerberg, M. [Mark]. (2018, March 21). I want to 
share an update on the Cambridge Analytica situation-including the steps we've already taken and our next steps to address this important issue [Face- book status update]. Retrieved from https://www. facebook.com/zuck/posts/10104712037900071

\section{About the Author}

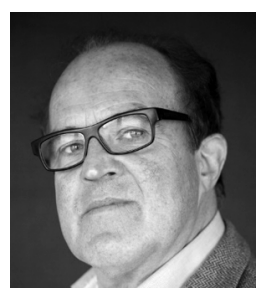

Jan Kleinnijenhuis (PhD Vrije Universiteit Amsterdam, 1990) is a Professor of Communication Science at the Vrije Universiteit Amsterdam. His research addresses the nature of political and economic news, news selection and agenda building, news effects, and methods for automated and semi-automated content analysis, or, text mining. 